\title{
Etude de l'interaction entre souches protéolytiques de streptocoques lactiques mésophiles et leurs variants non protéolytiques, au cours de leur croissance dans le lait
}

\author{
V. Juillard et J. Richard
}

Station de recherches laitières, INRA, 78350 Jouy-en-Josas, France

(reçu le 26 septembre 1988; accepté le 8 mars 1989)

Résumé - Afin de déterminer la nature des phénomènes d'interaction entre souches de streptocoques lactiques mésophiles protéolytiques et des variants non protéolytiques de ces souches lors de leur croissance dans le lait, 2 approches complémentaires sont développées : des cultures séquentielles (culture pure d'une souche suivie, après pasteurisation du lait, de la culture pure de l'autre souche) et des cultures en association.

L'étude en cultures séquentielles montre que la maturation du lait par une souche protéolytique a un effet inhibiteur sur la croissance d'un variant non protéolytique de cette souche et sur l'acidification du lait par ce variant. Plus le degré de maturation du lait est poussé, plus cette inhibition est marquée. Cet effet inhibiteur est également constaté dans la situation inverse : culture de la souche protéolytique sur un lait préalablement maturé par son variant non protéolytique.

Parallèlement, la conduite de cultures associant une souche protéolytique et son variant non protéolytique montre une diminution significative du taux de croissance de chaque souche. Cependant, la souche non protéolytique peut se développer plus longtemps et arriver à un niveau nettement supérieur à celui qu'elle atteint en culture pure. De plus, elle présente les caractéristiques de croissance de la souche parentale (phase exponentielle à 2 pentes).

L'ensemble de ces résultats montre que l'interaction existant entre une souche protéolytique et un de ses variants non protéolytiques ne se résume pas à un simple phénomène de commensalisme au profit de cette dernière, mais qu'il existe vraisemblablement des phénomènes concomitants de compétition, dont l'étude détaillée paraît nécessaire.

streptocoques lactiques mésophiles - variants non protéolytiques - croissance dans le lait - interaction

Summary - Study of the interaction between proteolytic strains of mesophilic lactic acid streptococci and non-proteolytic variants of these strains during their growth in milk. To determine the nature of the interaction between proteolytic strains of mesophilic lactic streptococci and their non-proteolytic variants, 2 complementary approaches are developped : sequential cultures (pure culture of one ot the 2 strains, followed by the culture of the other strain after pasteurization of the milk) and associative cultures of the 2 strains (prt+ and prt).

On one hand, sequential cultures show that maturation of the milk with a proteolytic strain lead to an inhibitory effect on the subsequent growth of its non-proteolytic variant and on the acid production by this variant. The more the milk is matured, the greater the inhibition. Such an effect is 
also observed during the culture of a proteolytic strain in a milk which has previously been matured with its non-proteolytic variant.

On the other hand, when a proteolytic strain is cultured in association with the corresponding non-proteolytic variant, the growth rate of the 2 strains is significantly reduced. However, the nonproteolytic variant can reach a higher level than in pure culture. Moreover, in association the nonproteolytic variant demonstrates a growth pattern similiar to that of the parent strain (i.e. two exponential phases of growth).

These results show that the interaction between a proteolytic and a non-proteolytic variant of the mesophilic lactic acid bacteria is not simply a commensalism to the benefit of the prt-variant, but that probably in the same time a more complex competitive phenomenon takes place in milk, which should be studied in details.

mesophilic lactic acid streptococci - non-proteolytic variants - growth in milk - interaction

\section{INTRODUCTION}

Les exigences nutritionnelles prononcées des bactéries lactiques ne leur permettent pas une croissance sur le lait aussi bonne que sur des bouillons riches (Pearce et al., 1974; Hugenholtz \& Veldkamp, 1985). L'explication de cette différence réside dans la faible concentration du lait en substances azotées facilement assimilables. Diverses études, basées sur des approches différentes, en témoignent : stimulation de la croissance par supplémentation du lait en diverses sources d'azotes riches en composés non protéiques (acides aminés libres et peptides) (Pearce et al., 1974; Selby Smith et al., 1975; Thomas \& Mills, 1981), comparaison de la teneur en acides aminés du lait avec les exigences des souches pour ces composés (Thomas \& Mills, 1981; Mills \& Thomas, 1981).

Cela semble en contradiction avec le fait que les bactéries lactiques disposent généralement d'un système protéolytique localisé au niveau de leur paroi, système qui fut mis en évidence et étudié en détail par de nombreux chercheurs (voir revue de Thomas \& Pritchard, 1987). Toutefois, la faible action protéolytique des streptocoques lactiques mésophiles sur la fraction azotée protéique du lait a été souli- gnée (Kikuchi et al., 1973). On peut donc penser que la vitesse à laquelle s'effectue la protéolyse du lait ne permet pas un approvisionnement suffisamment rapide des bactéries lactiques en substances azotées facilement assimilables pour que leur taux de croissance maximal soit atteint (Hugenholtz et al., 1987a).

L'origine plasmidique des gènes codant pour les protéases de paroi des bactéries lactiques a été démontrée par les travaux de McKay \& Baldwin (1975) et de Efstathiou \& McKay (1976). La perte de ce plasmide donne des souches qui, en cultures pures dans le lait, atteignent une densité de population plus faible que celle atteinte par la souche parentale et coagulent plus lentement le lait (ce sont les slow coaguling variants de Lawrence et al., 1976). Ces variants non protéolytiques (prt) possèdent tout de mẻme un équipement peptidasique et un système de transport des peptides analogues à ceux de la souche parentale prt+ (Exterkate, 1976; Van Boven \& Konings, 1986), ce qui leur permet de se développer dans le lait, tant que ce milieu contient des substances azotées facilement assimilables. Cela ne signifie pas pour autant qu'ils s'y multiplient à la même vitesse que la souche parentale : si certains auteurs ont mis en évidence un taux de croissance 
identique chez les deux souches (Citti et al., 1965; Thomas \& Mills, 1981), d'autres, en revanche, ont observé des vitesses différentes selon le $\mathrm{pH}$ ou le milieu de culture (Pearce et al., 1974; Otto, 1981; Hugenholtz et al., 1987b). De leur côté, Pearce et al. (1974) ont mis en évidence des taux de croissance différents entre un variant prt et sa souche parentale seulement lors de cultures sur lait; sur un bouillon riche, les 2 souches avaient le même taux de croissance.

Le comportement du variant prt dans le lait dépend sans doute de plusieurs facteurs, dont la concentration de ce milieu en substrats azotés facilement assimilables. Bien que cela ne soit pas établi de façon claire, on admet généralement que le variant prt, lorsqu'il est cultivé en présence de sa souche mère, bénéficie des produits de protéolyse du lait par la souche parentale, sans que la croissance de cette dernière en soit affectée (Pearce, 1970; Stadhouders, 1975; Otto, 1981), ce qui illustre parfaitement la relation de commensalisme (Meers, 1973). Dans de telles conditions, la croissance des variants prt dans le lait ne devrait donc être limitée que par l'acidification de ce milieu, comme c'est le cas pour la souche $\mathrm{prt}^{+}$.

La fréquence d'apparition spontanée de ces variants prt, au sein d'une culture de soụches $\mathrm{prt}^{+}$, est de l'ordre de $2 \%$ (Harriman \& Hammer, 1931). En principe, cette apparition ne devrait pas modifier le comportement de la souche parentale dans le lait, puisque celle-ci est très largement dominante. En admettant que les vitesses de croissance de la souche parentale et du variant ne sont pas très différentes, on peut s'attendre à ce qu'en fin de culture le rapport prt+prt ne soit pas éloigné de ce qu'il était au moment de l'apparition du variant prt. La situation est sans doute tout à fait différente dans le cas d'intérêt technologique où ce rapport est fixé volontairement à un niveau très différent de ce qu'il peut être naturellement : fabrication de fromages avec du lait contenant plus de souches prt que de souches $\mathrm{prt}^{+}$, de façon à éviter une trop grande acidité du caillé et la formation de peptides amers (Mills \& Thomas, 1980) : compte tenu de l'insuffisance de la vitesse de protéolyse des souches protéolytiques, la relation de commensalisme existant entre les 2 souches pourrait être modifiée, entraînant un changement dans le rapport entre les souches au cours de la culture. Toutefois, en raison de cette activité protéolytique chez les souches parentales, on peut penser que la maturation du lait par ces souches, préalable à la fabrication du fromage avec un levain dominé par des souches prt, devrait favoriser la croissance ultérieure des souches non protéolytiques. Inversement, le fait de cultiver préalablement un lait avec des variants non protéolytiques devrait provoquer un appauvrissement du lait en nutriments azotés directement assimilables, de telle sorte qu'une culture ultérieure de souches $\mathrm{prt}^{+}$ne pourrait pousser que grâce à leur activité protéolytique.

Compte tenu de toutes ces incertitudes, il nous est apparu intéressant d'étudier en détail le comportement de ces 2 types de souches dans ces différentes situations.

\section{MATÉRIELS ET MÉTHODES}

\section{Souches et milieu de culture}

L'étude a été conduite sur 6 souches protéasepositives de Lactococcus lactis subsp. lactis (Schleifer et al., 1985) et 1 variant protéasenégative de chacune d'elles. Dans ce texte, 
pour plus de clarté, nous conserverons la nomenclature du manuel de Bergey (Hardie, 1986) : ainsi, il s'agissait exactement de 5 couples de Streptococcus lactis subsp. lactis (CNRZ 141, 145, 261, 377 et 1076) et d'1 couple de $S$. lactis subsp. diacetylactis (CNRZ 125) que l'on dénommera plus simplement $S$. lactis et $S$. diacetylactis, respectivement.

Ces souches proviennent de la collection du Centre de recherches de Jouy-en-Josas. Elles étaient conservées sur lait écrémé tournesolé stérile à $-20^{\circ} \mathrm{C}$. Avant chaque utilisation, un repiquage était réalisé sur lait écrémé reconstitué, stérilisé par autoclavage à $115^{\circ} \mathrm{C}$ pendant $15 \mathrm{~min}$. Une série de tubes était ensemencée à des niveaux dégressifs obtenus par dilutions décimales. Le premier tube non coagulé après 16 à $18 \mathrm{~h}$ d'incubation à $30^{\circ} \mathrm{C}$ servait à ensemencer le lait.

Tous les essais étaient conduits à $30^{\circ} \mathrm{C}$, sur du lait écrémé reconstitué à $10 \%$ dans de l'eau stérile à partir de poudre Low-Heat Nilac (Nizo, Ede, Pays-bas).

\section{Conduite des cultures}

\section{Cultures séquentielles}

La mise en œuvre des cultures séquentielles était réalisée en 5 étapes : 1) pasteurisation du lait à $63^{\circ} \mathrm{C}$ pendant $30 \mathrm{~min} ; 2$ ) première culture, jusqu'au degré de maturation voulu, estimé sur la base du $\mathrm{pH}$; 3) réajustement du $\mathrm{pH}$ à $6,8 ; 4)$ deuxième pasteurisation à $63^{\circ} \mathrm{C}$ pendant $30 \mathrm{~min} ; 5)$ seconde culture, jusqu'à un niveau qui sera précisé lors de chaque expérience.

Pour chaque essai, une culture témoin était réalisée sur du lait non maturé, mais ayant subi deux pasteurisations successives pour simuler les étapes 1 et 4 ci-dessus. De plus, au début de l'étude, nous avons réalisé des cultures sur du lait acidifié artificiellement par de l'acide lactique puis neutralisé (simulation des étapes 2 et 3 ), et sur du lait additionné de cellules mortes ( $\mathrm{prt}^{+}$ou prt', selon le cas), de façon à déterminer leur influence sur le comportement de la souche utilisée en deuxième culture. Ces bactéries étaient préalablement cultivées sur milieu liquide M 17 (Terzaghi \& Sandine, 1975), récoltées par centrifugation, rincées en 2 fois avec une solution de $\mathrm{NaCl}$ à $0,85 \%$, incorporées au lait, et enfin tuées par pasteurisation du lait à $63^{\circ} \mathrm{C}$ pendant $30 \mathrm{~min}$. La numération réalisée à l'issue de ce traitement thermique mettait en évidence une population résiduelle tout à fait négligeable par rapport à la population étudiée en deuxième culture : $10^{3} \mathrm{ufc} / \mathrm{ml}$ (unité formant colonie) au plus pour la première, contre $10^{6}$ à $10^{7} \mathrm{ufc} / \mathrm{ml}$ pour la deuxième, au début de la seconde culture.

\section{Cultures en association}

La conduite de cultures en association se faisait en ensemençant 3 flacons de lait pasteurisé à $63^{\circ} \mathrm{C}$ pendant $30 \mathrm{~min}$. Le premier était ensemencé avec la souche $\mathrm{prt}^{+}$, à un niveau initial de l'ordre de $10^{6} \mathrm{ufc} / \mathrm{ml}$; le second l'était avec la souche $\mathrm{prt}^{-}$à un niveau d'environ $10^{7}$ $\mathrm{ufc} / \mathrm{ml}$; le troisième enfin était ensemencé avec les 2 souches $\mathrm{prt}^{+}$et prt à des niveaux respectifs de l'ordre de $10^{6}$ et $10^{7}$ ufc/ml. Toutes les $30 \mathrm{~min}$, les flacons étaient agités manuellement de manière à minimiser l'incorporation d'air dans le lait, puis le $\mathrm{pH}$ était mesuré et réajusté sur la valeur de $\mathrm{pH}$ la plus élevée des 3 cultures, par addition d'une solution de soude stérile. Cela permettait d'obtenir une évolution de $\mathrm{pH}$ de même ordre dans les 3 cultures, et rendait donc possible la comparaison entre cellesci.

\section{Dénombrements microbiens}

Dans le cas de cultures séquentielles, le niveau de population bactérienne du lait était estimé par dénombrement des colonies sur le milieu M 17 (Terzaghi \& Sandine, 1975), après 24 h d'incubation à $30^{\circ} \mathrm{C}$. Les chaînes de streptocoques étaient préalablement rompues par un traitement du lait pendant $30 \mathrm{~s}$ avec un agitateur Ultra-Turrax tournant à 20000 tours/min (Martley, 1972); le milieu de dénombrement était ensemencé en surface à l'aide d'un ensemenceur spiral (Spiral System, modèle DS, Interscience), et le comptage des colonies était effectué à l'aide d'un compteur électronique à laser (Bacteria Colony Counter, modèle $500 \mathrm{~A}$. Interscience). La validité et la précision de cette méthode de dénombrement ont été précédemment étudiées (Richard, 1982; Deschamps \& Richard, 1987). De plus, en début et en fin de toute culture, les caractères acidifiant et protéolytique des souches étaient vérifiés par ensemencement du lait à la surface du milieu gélosé 
FSDA (Fast-Slow Differential Agar, Huggins \& Sandine, 1984) : les souches $\mathrm{prt}^{+}$donnent de grosses colonies bombées et opaques, tandis que les souches prt se développent en donnant de plus petites colonies, plates et translucides; I'acidification se manifeste par la présence d'un halo rose autour des colonies, dû au virage du tournesol.

Dans le cas de cultures en association, le dénombrement séparé des souches prt+ et des souches prt' était réalisé par ensemencement en surface du milieu FSDA. Le nombre total de colonies ( $\mathrm{prt}^{+}$et $\mathrm{prt}^{-}$) dénombré sur ce milieu était tout à fait comparable à celui obtenu sur milieu non sélectif M17 utilisé en parallèle.

\section{RÉSULTATS}

\section{Cultures séquentielles}

Effet de la maturation du lait par les souches prt' sur la croissance ultérieure des variants prt correspondants

Les essais ont été conduits sur l'ensemble des souches (5 couples de souches de $S$. lactis et 1 de $S$. diacetylactis).

Une faible vitesse d'acidification du lait (diminution de $\mathrm{pH}$ inférieure à 0,5 unité $\mathrm{pH}$ en $6 \mathrm{~h}$ ) caractérise les souches prt (les slow coagulating variants de Lawrence et al., 1976). Sur l'ensemble des couples de souches étudiés, une évolution de $\mathrm{pH}$ encore plus faible était constatée lorsque le lait était préalablement maturé par les souches parentales $\mathrm{prt}^{+}$ (Fig. 1). Deux comportements différents pouvaient être dégagés selon les souches : soit une différence nette entre les évolutions de $\mathrm{pH}$ sur lait non maturé et sur lait maturé, qui s'amplifiait avec la durée de culture (souches $S$. lactis CNRZ $1076,145,377$ et 261 ), soit une différen- ce moins marquée de l'évolution de $\mathrm{pH}$ entre les 2 types de lait, qui s'amenuisait avec la durée de culture (souches S. lactis CNRZ 141 et $S$. diacetylactis CNRZ 125).

Dans tous les cas, cette moins bonne acidification du lait était accompagnée d'une croissance des souches prt' sur lait maturé par les souches $\mathrm{prt}^{+}$correspondantes très nettement inférieure à celle sur lait non maturé (Fig. 2). Au-delà de 6 h de culture, la différence entre les 2 cultures restait très marquée (souches CNRZ 1076, 145, 377 et 261) ou au contraire s'estompait (souches CNRZ 141 et 125).

Des essais complémentaires ont montré que l'acidification artificielle du lait suivie d'une neutralisation ou la présence de cellules tuées ne modifiaient pas significativement le comportement de la souche cultivée en second : la croissance de celle-ci et l'acidification du lait qui en résultait n'étaient pas significativement différentes de celles obtenues sur lait témoin. On peut donc bien attribuer les différences de croissance et d'acidification observées entre la culture sur lait maturé et celle sur lait témoin à la maturation du lait et non à un possible artéfact lié à la procédure expérimentale.

L'effet négatif de la maturation du lait par des souches prt' sur la croissance des variants prt et sur l'acidification du lait étant générale, l'étude a été poursuivie sur un seul couple de souches: S. lactis CNRZ $1076\left(\mathrm{prt}^{+}\right)$et un variant prt de cette souche, S. lactis CNRZ 1075.

Influence du degré de maturation du lait par une souche prt+ sur la culture ultérieure du variant prt correspondant

Quatre niveaux croissants de maturation du lait par S. lactis CNRZ 1076 ont été 
réalisés. L'acidification de chacun de ces 4 échantillons par S. lactis CNRZ 1075 a été comparée à celle du lait non maturé (Fig. 3).

La moins bonne acidification du lait maturé, quel que soit son degré de maturation, a été de nouveau constatée, mais l'évolution du $\mathrm{pH}$ différait selon le niveau atteint par la souche $\mathrm{prt}^{+}$lors de cette
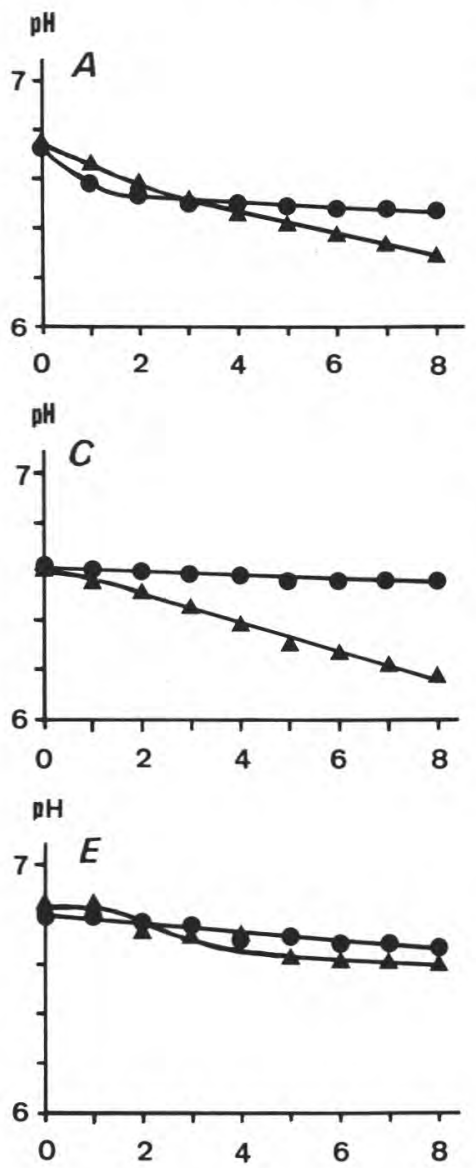

DUREE DE maturation. Pour un niveau inférieur à $10^{8}$ ufc/ml (Fig. $3 \mathrm{~A}$ et B), le pH du lait maturé s'abaissait régulièrement durant la culture de la souche prt, mais avec une vitesse diminuant avec le degré de maturation. Pour un niveau supérieur à $10^{8} \mathrm{ufc} / \mathrm{ml}$ (Fig. $3 \mathrm{C}$ et $\mathrm{D}$ ), le $\mathrm{pH}$ du lait maturé ne diminuait que pendant les premières heures de la culture de la souche prt;
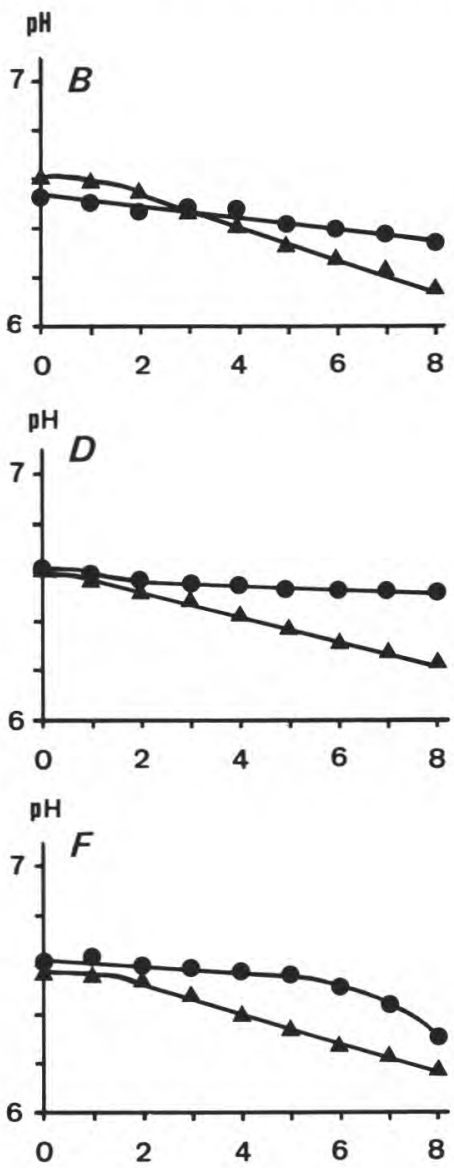

CULTURE $(\mathrm{H})$

Fig. 1. Effet de la maturation du lait par une souche protéolytique sur l'évolution du pH du lait durant la culture ultérieure d'un variant non protéolytique de cette souche. Niveaux atteints par les souches $\mathrm{prt}^{+}(\mathrm{ufc} / \mathrm{ml}): \mathrm{A}: 4,3 \cdot 10^{8}$ (S. lactis CNRZ 1076); B : 8,0 108 (S. lactis CNRZ 145); C : 1,2 • $10^{9}$ (S. lactis CNRZ 377); D : 6,1 $10^{8}$ (S. lactis CNRZ 261); $\mathrm{E}: 1,1 \cdot 10^{8}$ (S. lactis CNRZ 141); $\mathrm{F}: 1,3 \cdot$ $10^{9}$ (S. diacetylactis CNRZ 125); $\mathbf{\Delta},-$ culture respectivement sur lait témoin et sur lait maturé. 
plus le degré de maturation était élevé, plus cette diminution de $\mathrm{pH}$ était de courte durée ( $2 \mathrm{~h}$ pour un lait maturé jusqu'à un niveau de $4,3.10^{8} \mathrm{ufc} / \mathrm{ml}$, contre $1 \mathrm{~h}$ pour un lait maturé jusqu'à un niveau de $3,0.10^{9} \mathrm{ufc} / \mathrm{ml}$ ). Par la suite, le $\mathrm{pH}$ restait relativement stable.

Ce ralentissement de l'acidification par la souche prt- du lait maturé par la souche $\mathrm{prt}^{+}$était accompagné d'une moins bonne croissance de la souche prt, quel que soit le degré de maturation du lait (Fig. 4). On notera cependant que, pour de faibles degrés de maturation (niveau atteint par la souche $\mathrm{prt}^{+}$inférieur à $10^{8} \mathrm{ufc} / \mathrm{ml}$, Fig. 4 $A$ et $B$ ), l'écart de population bactérienne entre un lait maturé et un lait non maturé tendait à diminuer après $8 \mathrm{~h}$ de culture. En revanche, pour des degrés de maturation du lait plus importants (niveau atteint par la souche $\mathrm{prt}^{+}$supérieur à $10^{8} \mathrm{ufc} / \mathrm{ml}$, Fig. $4 \mathrm{C}$ et $\mathrm{D}$ ), la culture de la souche prt sur lait maturé était arrêtée avant $6 \mathrm{~h}$, l'augmentation de population entre 6 et $8 \mathrm{~h}$ d'incubation étant nulle.

Effet de la maturation du lait par le variant prt sur la croissance ultérieure de la souche parentale prt+

La souche prt+ S. lactis CNRZ 1076 était cultivée soit sur du lait non maturé, soit sur du lait maturé par son variant prt CNRZ 1075. La concentration cellulaire atteinte par la souche prt au cours de la culture préalable était de l'ordre de $10^{8} \mathrm{ufc} / \mathrm{ml}$ (ce qui correspond au niveau maximum que peut atteindre cette souche dans ces conditions de culture). L'effet de la maturation était analysé en comparant

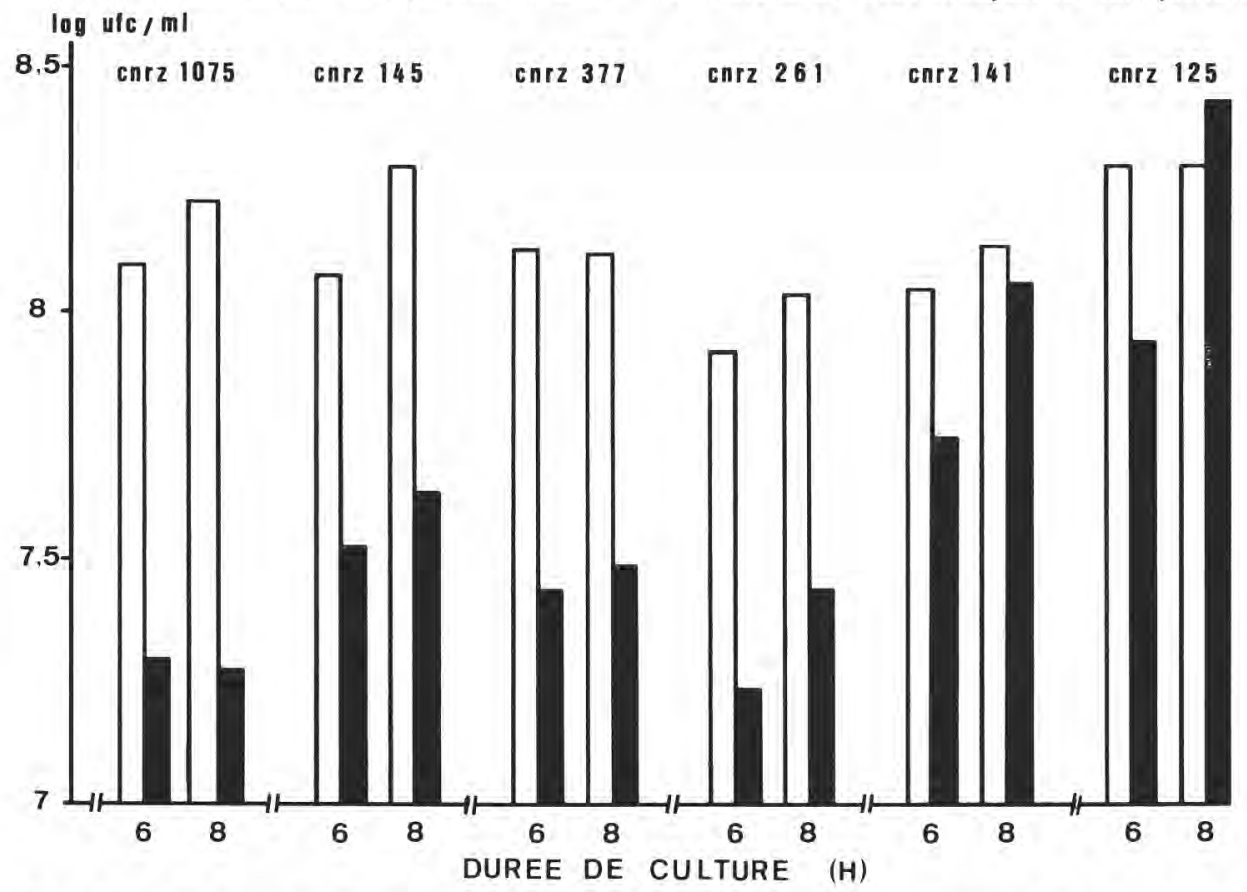

Fig. 2. Effet de la maturation du lait par une souche protéolytique sur le niveau de population atteint en 6 ou $8 \mathrm{~h}$ de culture à $30^{\circ} \mathrm{C}$ par son variant non protéolytique cultivé en second. Les niveaux de population atteints par les souches prt+ sont indiqués Figure 1. $\square, \mathbf{0}=$ culture respectivement sur lait témoin et sur lait maturé. 
les niveaux de population et le $\mathrm{pH}$ des 2 laits après $6 \mathrm{~h}$ de culture. Compte tenu du fait que l'analyse ne portait que sur une seule durée de culture de la souche $\mathrm{prt}^{+}$, l'expérience a été répétée 4 fois.

L'acidification du lait maturé était moins importante que celle du lait non maturé (Tableau I). L'écart de $\mathrm{pH}$ variait, selon les essais, de 0,2 à 0,5 unité. De même, on constatait que le niveau atteint par la souche $\mathrm{prt}^{+}$était systématiquement moins élevé sur le lait maturé que sur le lait témoin : les écarts s'échelonnaient, selon les répétitions, de $2 \times 10^{8}$ à près de $10^{9} \mathrm{ufc} / \mathrm{ml}$, ce qui représentait 11 à $35 \%$ de la population totale de la souche prt $^{+}$ sur le lait témoin. Comme on peut le voir
Tableau I. Différences de comportement de la souche protéolytique $S$. lactis CNRZ 1076, après $6 \mathrm{~h}$ de culture sur lait maturé par son variant non protéolytique CNRZ 1075, par rapport à sa culture sur lait témoin.

\begin{tabular}{llll}
$\begin{array}{c}\text { Essai } \\
\text { Niveau atteint par } \\
\text { la souche prt } \\
\text { (ufc/ml) }\end{array}$ & $\begin{array}{l}\text { Souche prt+ } \\
\text { Ecart de Ecart de } \\
\text { pH }\end{array}$ & $\begin{array}{c}\text { Eopulation } \\
\text { pon }\end{array}$ \\
\hline & $1,7 \times 10^{8}$ & $-0,53$ & $-2 \times 10^{8}$ \\
2 & $1,8 \times 10^{8}$ & $-0,23$ & $-5 \times 10^{8}$ \\
3 & $2,0 \times 10^{8}$ & $-0,42$ & $-8 \times 10^{8}$ \\
4 & $1,1 \times 10^{8}$ & $-0,54$ & $-9,5 \times 10^{8}$ \\
\hline
\end{tabular}

Niveau atteint par la souche prt+ dans le lait témoin (ufc/ml) : 2,2.109; $\mathrm{pH}: 5,25$.

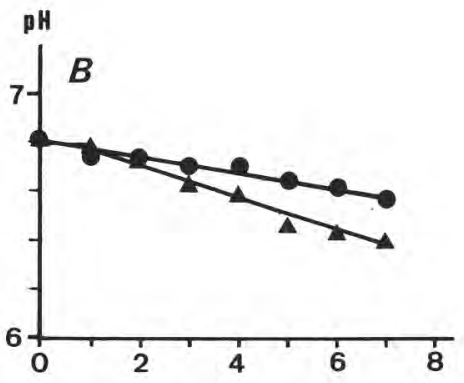

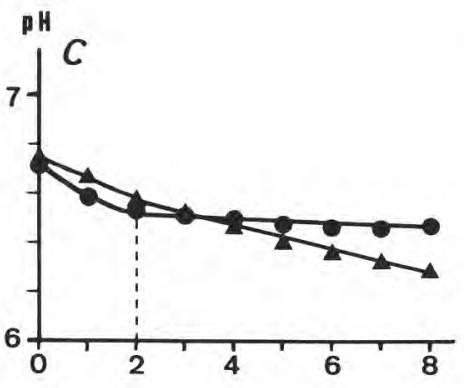

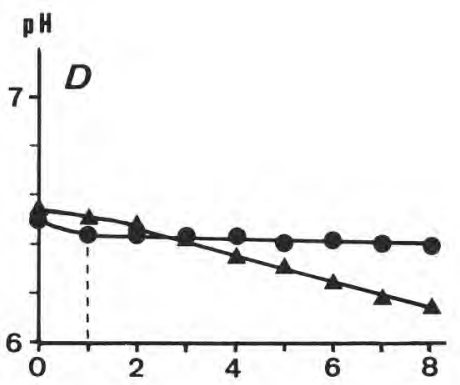

DUREE DE CULTURE (H)

Fig. 3. Effet du degré de maturation du lait par la souche protéolytique S. lactis CNRZ 1076 sur l'évolution du $\mathrm{pH}$ du lait durant la culture ultérieure du variant non protéolytique (CNRZ 1075) de cette souche. Niveaux atteints par la souche $\mathrm{prt}^{+}$(ufc/ml) A : 3,7 • 10 7 , B : 8,6 $\cdot 10^{7}, \mathrm{C}: 4,3 \cdot 10^{8}$, $\mathrm{D}: 3,0 \cdot 10^{9} ; \mathbf{\Delta}, \mathbf{c}$ comme pour Fig. 1 . 
sur le Tableau I, la variabilité des écarts de $\mathrm{pH}$ et de concentration cellulaire entre le lait témoin et le lait maturé par la souche prt, d'une répétition à l'autre, ne peut être attribuée à des variations de niveau cellulaire atteint lors de la culture préalable de la souche prt.

\section{Cultures associant une souche prt' et un de ses variants prt}

Le $\mathrm{pH}$ du lait évolue de façon très différente, selon qu'il est fermenté par la souche $\mathrm{prt}^{+}$ou par un de ses variants prt. Lors d'une culture associant ces 2 souches, l'évolution du $\mathrm{pH}$ dépend du niveau de chaque souche : la courbe de $\mathrm{pH}$ est donc intermédiaire entre les courbes de $\mathrm{pH}$ des cultures pures. Par conséquent, il est difficile de comparer la croissance des 2 souches en association avec la croissance en culture pure, puisque le taux de croissance de chacune peut considérablement varier avec le $\mathrm{pH}$

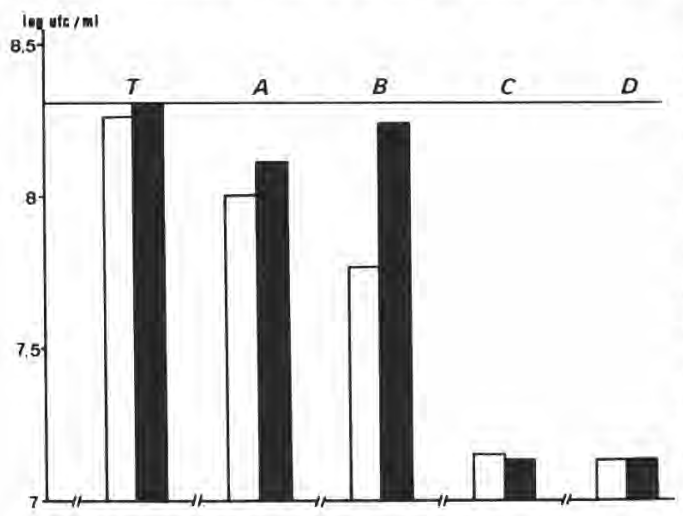

Fig. 4. Effet du niveau cellulaire atteint par la souche protéolytique S. lactis CNRZ 1076 dans le lait sur la croissance ultérieure de son variant non protéolytique CNRZ 1075. Niveau de $\mathrm{S}$. lactis CNRZ 1076 (ufc/ml) : T : témoin, A : $3,7 \cdot 10^{7}, \mathrm{~B}: 8,6 \cdot 10^{7}, \mathrm{C}: 4,3 \cdot 10^{8}, \mathrm{D}$ : $3,0 \cdot 10^{9} ; \square$, ․ㅜㄹ : niveau de $S$. lactis CNRZ 1075 après respectivement 6 et $8 \mathrm{~h}$ de culture.
(Otto, 1981; Hugenholtz et al., 1987b). C'est pourquoi, dans cette partie de l'étude, les cultures pures et associées ont été conduites avec un réajustement permanent de $\mathrm{pH}$. Pendant les 4 premières heures d'incubation, le $\mathrm{pH}$ de la culture en association et celui de la culture de la souche prt étaient ajustés sur celui de la culture de la souche $\mathrm{prt}^{+}$(acidification du lait la plus lente, en raison du faible niveau d'ensemencement de cette souche : de l'ordre de $10^{6} \mathrm{ufc} / \mathrm{ml}$ ). Par la suite, le $\mathrm{pH}$ de la culture en association et celui de la culture de la souche $\mathrm{prt}^{+}$ étaient ramenés aux valeurs de $\mathrm{pH}$ de la culture de la souche prt (variant acidifiant lentement le lait). Les variations de $\mathrm{pH}$ lors de chaque ajustement ne dépassaient jamais 0,6 unité. L'expérience a été réalisée à 2 reprises.

La Figure 5 montre les résultats obtenus lors de la première répétition. Ceux de la deuxième expérience étaient tout à fait comparables. II apparaît nettement que la souche prt était stimulée lorsqu'elle était cultivée en association avec sa souche parentale $\mathrm{prt}^{+}$: sa densité de population, en fin de culture, augmentait d'un facteur 5 environ. En revanche, la souche $\mathrm{prt}^{+}$était sensiblement inhibée : sa densité de population diminuait d'un facteur 2,5 environ. De plus, le comportement de la souche prt était modifié. Alors qu'en culture pure la phase de croissance exponentielle apparaîssait linéaire (Hassan et al., 1989), elle devenait nettement biphasique en culture associée: la souche prt continuait de pousser au-delà du niveau de population normalement atteint en culture pure (de l'ordre de $10^{8} \mathrm{ufc} / \mathrm{ml}$ ), mais avec un taux de croissance plus faible que lors de la première phase. La souche prt se comportait donc comme sa souche mère, qui présente ce type de croissance biphasique (Hassan et al., 1989). 
Les résultats de l'analyse de régression linéaire effectuée sur les phases de croissance apparemment exponentielle des 2 souches sont présentés dans le Tableau II. Les valeurs parfois élevées (supérieures à 0,1 ) de l'écart type de régression $\left(S_{y, x}\right)$ traduisent un ajustement plutôt moyen des points expérimentaux à la droite de régression (Hassan et al., 1989). Néanmoins, la reproductibilité des valeurs de pente est suffisamment bonne pour permettre des comparaisons, pour chaque souche, entre cultures pures et cultures en association. Avec la souche $\mathrm{prt}^{+}$, on constate que la durée des 2 phases de croissance exponentielle n'est pas changée du fait de l'association avec la souche prt. En revanche, le taux de croissance de la souche $\mathrm{prt}^{+}$, pour chaque phase, est nettement diminué. Pour la souche prt, l'association a un double effet : d'une part, celui d'augmen-

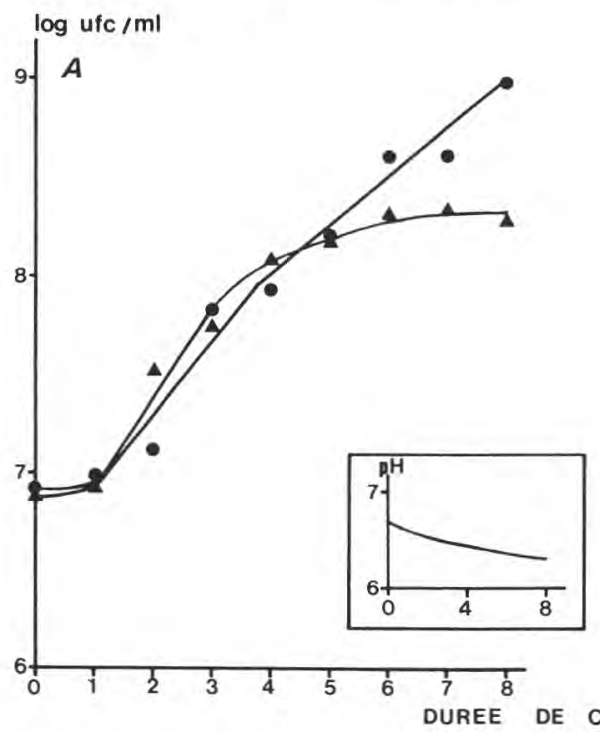

Fig. 5. Cultures de S. lactis CNRZ 1076 et de son variant non protéolytique (CNRZ 1075), seules ou en association, suivant une évolution imposée de pH. A. : S. lactis CNRZ 1075 (prt); B : S. lactis CNRZ 1076 (prt+); = cultures en association; $\boldsymbol{\Delta}$ : cultures pures.

Encadré : Evolution imposée du pH (toutes les $30 \mathrm{~min}$, le $\mathrm{pH}$ des cultures était réajusté sur la valeur de $\mathrm{pH}$ la plus élevée par addition de soude stérile). Les écarts de $\mathrm{pH}$ mesurés avant réajutement n'excédaient jamais 0,6 unités $\mathrm{pH}$ ). ter de $1 \mathrm{~h}$ la première phase de croissance exponentielle et d'en faire apparaître une deuxième, d'une durée au moins égale à $4 \mathrm{~h}$; d'autre part, celui de diminuer le taux de croissance de la souche prt durant cette première phase de croissance, par rapport à la culture pure. On notera enfin que la vitesse de multiplication de la souche prt, cultivée en association avec sa souche parentale, est faible dans cette deuxième phase : de l'ordre de 0,2 unité de log (ufc/ml) par h, soit un doublement de population toutes les $80 \mathrm{~min}$.

\section{DISCUSSION}

L'interaction entre une souche protéolytique et l'un de ses variants non protéoly-

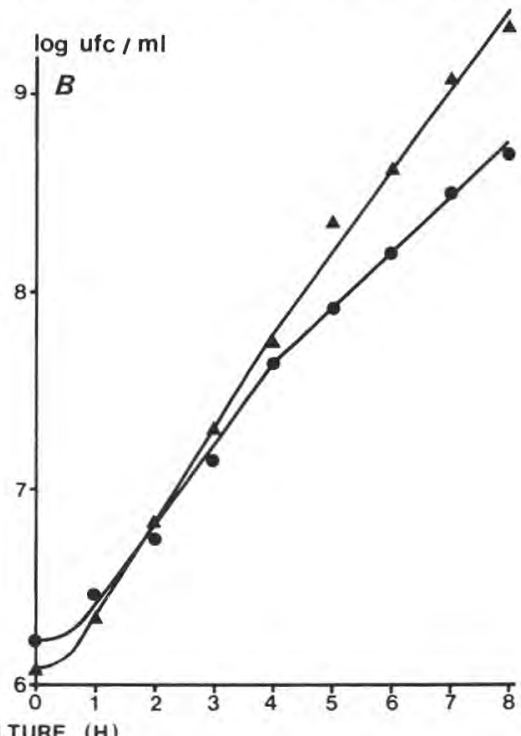


Tableau II. Caractéristiques principales des courbes de croissance de $S$. lactis CNRZ 1076 et de son variant non protéolytique CNRZ 1075, cultivés ensemble ou séparément dans du lait, suivant une évolution imposée de $\mathrm{pH}$.

\begin{tabular}{|c|c|c|c|c|c|c|c|c|}
\hline \multirow{2}{*}{ Souche } & \multirow{2}{*}{$\begin{array}{l}\text { Type de } \\
\text { culture }\end{array}$} & \multirow{2}{*}{ Essai } & \multicolumn{3}{|c|}{$\begin{array}{l}\text { Première phase } \\
\text { de croissance }\end{array}$} & \multicolumn{3}{|c|}{$\begin{array}{l}\text { Deuxième phase } \\
\text { de croissance }\end{array}$} \\
\hline & & & Intervalle & $S_{y, x}$ & Pente & Intervalle & $S_{y, x}$ & Pente \\
\hline \multirow{2}{*}{$\mathrm{prt}^{+}$} & pure & $\begin{array}{l}1 \\
2 \\
m\end{array}$ & $\begin{array}{l}1-4 \\
1-4\end{array}$ & $\begin{array}{l}0,03 \\
0,03\end{array}$ & $\begin{array}{l}0,47 \\
0,53 \\
0,50\end{array}$ & $\begin{array}{l}4-8 \\
4-8\end{array}$ & $\begin{array}{l}0,11 \\
0,09\end{array}$ & $\begin{array}{l}0,39 \\
0,30 \\
0,35\end{array}$ \\
\hline & associée & $\begin{array}{l}1 \\
2 \\
m\end{array}$ & $\begin{array}{l}1-4 \\
1-4\end{array}$ & $\begin{array}{l}0,08 \\
0,08\end{array}$ & $\begin{array}{l}0,40 \\
0,30 \\
0,35\end{array}$ & $\begin{array}{l}4-8 \\
4-8\end{array}$ & $\begin{array}{l}0,03 \\
0,14\end{array}$ & $\begin{array}{l}0,27 \\
0,31 \\
0,29\end{array}$ \\
\hline \multirow{2}{*}{ prt } & pure & $\begin{array}{l}1 \\
2 \\
m\end{array}$ & $\begin{array}{l}1-3 \\
1-3\end{array}$ & $\begin{array}{l}0,16 \\
0,06\end{array}$ & $\begin{array}{l}0,40 \\
0,50 \\
0,45\end{array}$ & $\begin{array}{l}\text { NO } \\
\text { NO }\end{array}$ & $\begin{array}{l}\text { NO } \\
\text { NO }\end{array}$ & $\begin{array}{l}\text { NO } \\
\text { NO }\end{array}$ \\
\hline & associée & $\begin{array}{l}1 \\
2 \\
m\end{array}$ & $\begin{array}{l}1-4 \\
1-4\end{array}$ & $\begin{array}{l}0,08 \\
0,13\end{array}$ & $\begin{array}{l}0,36 \\
0,42 \\
0,39\end{array}$ & $\begin{array}{l}4-8 \\
4-8\end{array}$ & $\begin{array}{l}0,03 \\
0,13\end{array}$ & $\begin{array}{l}0,25 \\
0,20 \\
0,23\end{array}$ \\
\hline
\end{tabular}

Intervalle : période (en h) sur laquelle porte l'analyse de régression; Sy, $x$ : écart type de régression; pente : pente de croissance, exprimée en log (ufc/ml) par $\mathrm{h} ; \mathrm{m}$ : moyenne de 2 déterminations; NO : non observé; les conditions de culture sont indiquées Fig. 5 , et les analyses de régression linéaire sont faites sur chacune des 2 phases de croissance, voir exemple Fig. 5.

tique, lorsqu'ils sont cultivés en association, a été définie comme étant un commensalisme par plusieurs auteurs (Pearce, 1970; Stadhouders, 1975; Otto, 1981). Une interaction de telle nature permettrait de supposer que la maturation du lait par la souche prt+ enrichit ce milieu en substances azotées facilement assimilables (produits de protéolyse), ce qui aurait stimulé la culture ultérieure du variant prt. Cette hypothèse était d'ailleurs renforcée par le fait que l'addition au lait de produits de protéolyse d'une souche de Streptococcus cremoris prt $^{+}$stimulait la croissance de son variant prt (Otto, 1981). Or, les résultats que nous avons obtenus montrent que les souches prt sont inhibées lorsqu'elles sont cultivées sur du lait préalablement maturé par les souches parentales prt+ correspondantes. II semble que cette inhibition soit un phénomène courant, puisqu'elle a été constatée sur les 6 couples de souches utilisés dans notre étude. Mais, par ailleurs, après $6 \mathrm{~h}$ de culture sur lait en association avec sa souche mère, la souche prt atteint une densité de populations nettement supérieure à celle obtenue en culture pure.

Ces 2 constatations paraissent en contradiction. Celle-ci pourrait provenir du fait que, entre les 2 types d'expériences réalisées, il existe une importante différence d'ordre méthodologique : dans le cas des cultures séquentielles, il y a destruc- 
tion, par pasteurisation du lait, des bactéries de la première culture. On peut donc avancer une première série d'hypothèses pour expliquer l'ensemble des résultats obtenus : la libération, par chacune des 2 souches, de substances affectant la croissance de l'autre souche. La souche prt libérerait donc dans le milieu de culture une substance inhibitrice thermorésistante agissant sur la souche $\mathrm{prt}^{+}$, tandis que cette dernière libérerait 2 types de substances, l'une inhibitrice et thermorésistante, l'autre stimulante et thermolabile. Ainsi, seul l'effet inhibiteur serait constaté avec les cultures séquentielles, la substance stimulante étant dénaturée au cours de la pasteurisation du lait faisant suite à la première culture. Toutefois, dans des cultures en association, pour expliquer la succession d'un effet inhibiteur sur la souche prt pendant la première phase de croissance, puis d'un effet stimulant sur cette même souche pendant la deuxième phase de croissance, il est nécessaire de supposer que pendant la première phase de croissance de la souche $\mathrm{prt}^{+}$l'effet inhibiteur est dominant, tandis que pendant la deuxième phase de croissance l'effet stimulant prédomine. Dès lors, on voit que cette première série d'hypothèses, dont certaines apparaîssent peu probables, induit un ensemble de relations très complexes entre la souche protéolytique et son variant.

Une seconde série d'hypothèses permettant d'expliquer l'ensemble des résultats est suggérée par les informations fragmentaires sur la nutrition azotée des streptocoques lactiques que l'on peut trouver dans la littérature. Au cours de la maturation du lait par les souches $\mathrm{prt}^{+}$, certains acides aminés libres et petits peptides présents naturellement dans le lait sont utilisés préférentiellement. Leur utilisation correspondrait à la première phase de croissance exponentielle constatée avec la souche $S$. lactis CNRZ
$1076 \mathrm{prt}^{+}$(Hassan et al., 1989). Le milieu s'épuisant en substrat azoté non protéique, l'activité protéolytique de la souche $\mathrm{prt}^{+}$se met alors en route. Cette activité tardive paraît confirmée par une observation de Exterkate (1985) : cet auteur a en effet montré que la synthèse des protéases de paroi d'une souche de $S$. cremoris était inhibée par l'addition au lait de peptides et d'acides aminés exogènes. Puisque la vitesse à laquelle s'effectue la protéolyse semble insuffisante (Hugenholtz et al., 1987a), l'apport au lait d'acides aminés et de peptides essentiels serait trop faible pour permettre le maintien du taux de croissance observé lors de la première phase de croissance exponentielle. Dans des conditions de culture en association, avec une proportion importante de la population bactérienne constituée de souches prt, on doit s'attendre, dans le cadre de cette seconde série d'hypothèses, à une compétition des 2 types de souches pour les acides aminés libres et les petits peptides. II doit logiquement en résulter une diminution du taux de croissance de chaque souche : c'est ce que nous avons effectivement observé. Après épuisement de cette source d'azote, l'activité protéolytique de la souche $\mathrm{prt}^{+}$doit subvenir aux besoins des 2 types de souches. Comme cette activité limite déjà la croissance de la souche $\mathrm{prt}^{+}$ en culture pure, il en résulte que la compétition des 2 souches pour les produits de protéolyse sera d'autant plus vive que la proportion de souches prt sera importante. Cela se traduit encore par une diminution du taux de croissance de la souche $\mathrm{prt}^{+}$pendant la deuxième phase de croissance exponentielle. En revanche, la souche prt peut continuer à se développer au-delà du niveau atteint en culture pure, tant que le $\mathrm{pH}$ du lait le permet, puisqu'elle bénéficie des produits de protéolyse de la souche parentale. 
Cette même série d'hypothèses permet également d'expliquer pourquoi la croissance d'une souche $S$. lactis prt+ est moindre après $6 \mathrm{~h}$ de culture sur un lait maturé par un variant prt de cette souche que sur un lait témoin : lors de la maturation, la souche prt consomme les substrats azotés directement assimilables (acides aminés libres et petits peptides), nécessaires à sa croissance. Lorsque la souche $\mathrm{prt}^{+}$est ensemencée, le lait est appauvri en substances azotées non protéiques. Cette carence du lait en acides aminés libres et en petits peptides pourrait donc être à l'origine de l'inhibition relative de la souche $\mathrm{prt}^{+}$. En effet, Mills \& Thomas (1981) ont démontré que, dans les phases initiales de la croissance des streptocoques lactiques mésophiles, les acides aminés libres du lait représentaient la source d'azote principalement utilisée par ces bactéries.

En conclusion, l'ensemble de nos résultats prouve que l'interaction entre une souche $\mathrm{prt}^{+}$et son variant $\mathrm{prt}$ au cours de leur croissance en association ou non dans le lait ne se limite pas à un simple phénomène de commensalisme (interaction au sein de laquelle la croissance d'une espèce est facilitée par la seconde espèce présente dans la communauté, la croissance de cette seconde espèce n'étant pas affectée par la présence de la première espèce. Meers, 1973). La nature de ces phénomènes d'interaction, très vraisemblablement une compétition entre les deux souches pour des composés azotés non protéiques, est actuellement à l'étude. Quelle qu'en soit sa nature, cette interaction induit des changements de vitesse d'acidification du lait qui sont sans doute d'une grande importance technologique.

\section{RÉFÉRENCES}

Citti J.E., Sandine W.E. \& Elliker P.R. (1965) Comparison of slow and fast acid-producing Streptococcus lactis. J. Dairy Sci. 48, 14-18

Deschamps N. \& Richard J. (1987) Evaluation d'un compteur de colonies à laser adapté aux boîtes de Petri ensemencées en spirale. Sci. Aliments, hors-série $\mathrm{n}^{\circ}$ VII, 165-169

Efstathiou J.D. \& McKay L.L. (1976) Plasmids in Streptococcus lactis : evidence that lactose metabolism and proteinase activity are plasmid-linked. Appl. Environ. Microbiol. 32, 38-44

Exterkate F.A. (1976) The proteolytic system of a slow-lactic-acid-producing variant of Streptococcus cremoris HP. Neth. Milk Dairy J. 30, 3-8

Exterkate F.A. (1985) A dual-directed control of cell wall proteinase production in Streptococcus cremoris $\mathrm{AM}_{1}$ : a possible mechanism of regulation during growth in milk. J. Dairy Sci. 68, 562-571

Hardie J.M. (1986) Genus Streptococcus Rosenbach 1884. In : Bergey's Manual of Systematic Bacteriology (P.H.A. Sneath, N.S. Mair \& M.E. Sharpe, eds). Williams \& Wilkins, Baltimore, pp. 1043-1047

Harriman L.A. \& Hammer B.W. (1931) Variations in the coagulation and proteolysis of milk by Streptococcus lactis. J. Dairy Sci. 14, 40-49

Hassan A.I., Deschamps N. \& Richard J. (1989) Précision des mesures des vitesses de croissance des streptocoques lactiques dans le lait basées sur la méthode de dénombrement microbien par formation de colonies. Lait (à paraître)

Hugenholtz J. \& Veldkamp H. (1985) Competition between different strains of Streptococcus cremoris. FEMS Microbiol. Ecol. 31, 57-62

Hugenholtz J., Dijkstra M. \& Veldkamp H. (1987a) Amino-acid limited growth of starter cultures in milk. FEMS Microbiol. Ecol. 45, 191198

Hugenholtz J., Splint R., Konings W.N. \& Veldkamp H. (1987b) Selection of protease-positive and protease-negative variants of Streptococcus cremoris. Appl. Environ. Microbiol. 53, 309314

Huggins A.M. \& Sandine W.E. (1984) Differenciation of fast and slow milk-coagulating isolates in strains of lactic streptococci. J. Dairy Sci. $67,1674-1679$ 
Kikuchi T., Desmazeaud M. \& Bergère J.L. (1973) Aptitude des streptocoques lactiques à la protéolyse. I. Etude de l'action de streptocoques lactiques mésophiles sur les constituants azotés du lait. Lait 53, 369-385

Lawrence R.C., Thomas T.D. \& Terzaghi B.E. (1976) Reviews of the progress of Dairy Science : cheese starters. J. Dairy Res. 43, 141-193

McKay L.L. \& Baldwin K.A. (1975) Plasmid distribution and evidence for a proteinase plasmid in Streptococcus lactis $\mathrm{C}_{2}$. Appl. Microbiol. 29, 546-548

Martley F.G. (1972) The effect of cell numbers in streptococcal chains on plate-counting. N.Z.J. Dairy Sci. Technol. 7, 7-11

Meers J.L. (1973) Growth of bacteria in mixed cultures. Crit. Rev. Microbiol. 2, 139-184

Mills O.E. \& Thomas T.D. (1980) Bitterness development in Cheddar cheese : effect of the level of starter proteinase. N.Z.J. Dairy Sci. Technol. 15, 131-141

Mills O.E. \& Thomas T.D. (1981) Nitrogen sources for growth of lactic streptococci in milk. N.Z.J. Dairy Sci. Technol. 16, 43-55

Otto R. (1981) An ecophysiological study of starter streptococci. Ph. D. Thesis, Université de Groningen, 21-31

Pearce L.E. (1970) Interactions stimulant la croissance parmi les streptocoques lactiques.

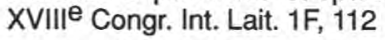

Pearce L.E., Skipper N.A. \& Jarvis B.D.W. (1974) Proteinase activity in slow acid- producing variants of Streptococcus lactis. Appl. Microbiol. 27, 933-937

Richard J. (1982) Dénombrement sélectif des bactéries du lait en fonction de la taille des colonies à l'aide d'un compteur électronique à laser. Sci. Aliments 2, 31-40

Schleifer K.H., Kraus J., Dvorak C., Killper-Bälz R., Collins M.D. \& Fischer W. (1985) Transfer of Streptococcus lactis and related Streptococci to the genus Lactococcus gen. nov. System. Appl. Microbiol. 6, 183-185

Selby Smith J., Hillier A.J., Lees G.J. \& Jago G.R. (1975) The nature of the stimulation of the growth of Streptococcus lactis by yeast extract. J. Dairy Res. 42, 123-138

Stadhouders J. (1975) Microbes in milk and dairy products. An ecological approach. Neth. Milk Dairy J. 29, 104-126

Terzaghi B.E. \& Sandine W.E. (1975) Improved medium for lactic streptococci and their bacteriophages. Appl. Microbiol. 29, 807-813

Thomas T.D. \& Mills O.E. (1981) Proteolytic enzymes of starter bacteria. Neth. Milk Dairy J. $35,255-273$

Thomas T.D. \& Pritchard G.G. (1987) Protéolytic enzymes of dairy starter cultures. FEMS Microbiol. Rev. 46, 245-268

Van Boven A. \& Konings W.N. (1986) The uptake of peptides by micro-organisms. Neth. Milk Dairy J. 40, 117-127 